\title{
The Fontan type procedure in patients with visceral heterotaxy
}

\author{
Hideki Uemura \\ Department of Cardiovascular Surgery, National Cardiovascular Center, Osaka, Japan
}

$\mathrm{F}$ RST OF ALL, MAINWARING AND LAMBERTI ARE to be congratulated for their report in this issue of the journal, ${ }^{1}$ in which they describe an excellent application of the extracardiac Fontan' procedure, using a Gore-Tex tube graft in patients with visceral heterotaxy. Obviously, vast improvements have been made in the surgical establishment of the Fontan circulation, particularly in those patients who have very complicated cardiac malformations unsuitable for biventricular repair, as opposed to the more classical' patients with straightforward tricuspid atresia or double inlet left ventricle. In those patients who have visceral heterotaxy, however, definitive conversion of the abnormal circulation into a non-cyanotic one remains one of the current surgical challenges. Our current experience suggests that overall results after total right heart bypass can be improved still further, particularly in patients with visceral heterotaxy, by combining appropriate background knowledge with thoughtful clinical considerations. Better results may be achieved in several ways. For instance, they may be promoted by more precise recognition of the morphologic spectrum in this particular setting, by more efficient uses of innovative technical devices, by taking advantage of recent developments in molecular biology and genetic backgrounds, and so on.

As has been well documented, the universally present abnormal venoatrial connections constitute one of the key issues which could militate against successful surgical interventions in patients with visceral heterotaxy. ${ }^{2-5}$ The cardiopulmonary bypass needed for most cardiac surgical procedures cannot

Correspondence to: H. Uemura, Department of Cardiovascular Surgery, National Cardiovascular Center, 5-7-1 Fujishirodai, Suita, Osaka 565-8565, Japan. Tel: (81) 6833-5012; Fax: (81) 6872-7486

Accepted for publication 1 June 1998 be efficiently established without precise knowledge of these connections. In order to accomplish cavopulmonary anastomoses for the Fontan type procedure, knowledge of the pattern of systemic venous drainage is self-evidently crucial. Construction of an unobstructed channel for pulmonary venous drainage is also of importance, not only in achieving the optimal Fontan procedure, but also when attempting biventricular repair. Pulmonary venous drainage via the systemic veins is common in hearts with isomeric right appendages, and connection of the pulmonary veins bilaterally to the atrial chambers, with a wide distance between their orifices, is seen with frequency in those with isomeric left appendages. ${ }^{3}$ The significance of the atrial arrangement becomes greater when the surgeon realizes that the manner of pulmonary venous connection is always abnormal in right isomerism even in those hearts in which the veins drain directly to the atrial cavity. ${ }^{3}$ These facts are of importance when considering classification and description.

Some investigators have suggested that cardiac situs can be determined according to the patterns of venoatrial connections. ${ }^{5} \mathrm{My}$ colleagues and I have encountered great difficulty in universally applying this concept in the setting of visceral heterotaxy. The specific patterns encountered are sufficiently variable, in our experience, to rule out diagnosis of atrial arrangement on the basis of the venoatrial connections. ${ }^{3}$ This is not to deny the importance of these venoatrial connections. As emphasized above, precise knowledge of the patterns is crucial for proper planning and execution of the surgical procedures. It is simply that these patterns cannot be used with precision to predict the morphologic arrangement of the most constant atrial component, namely the appendages. In this respect, therefore, we prefer to use the arrangement of the atrial appendages rather than the venoatrial connections or splenic 
status when stratifying the two well recognised subsets of patients with visceral heterotaxy. Indeed, several important differences are found when the patients are divided according to whether they have isomerism of the morphologically right as opposed to the left atrial appendages, this distinction itself being made on the morphology of the pectinate muscles within the appendages rather than according to their size or shape. ${ }^{3}$ Differences in the patterns of pulmonary venous connection has already been mentioned. Interruption of the inferior caval vein is almost always seen in left isomerism, ${ }^{3}$ although a recent review has documented rare cases of interruption in patients with asplenia, ${ }^{6}$ and we know of additional instances. ${ }^{7}$ The structural arrangement of the conduction system can also be related to the morphology of the atrial appendages. Presence of sinus nodes bilaterally is the rule in hearts with right isomerism, while hypoplasia or even aplasia of the sinus node is the rule in those with left isomerism. ${ }^{8-10}$ Abnormalities in the connection between the atrioventricular node and the ventricular conduction bundle have also been documented. ${ }^{10,11}$ Epicardial mapping during the operative procedure can be helpful in determining precisely the location of the atrial pacemaker, particularly in patients with left isomerism. ${ }^{12}$

Additional morphologic studies in hearts with isomeric atrial appendages have revealed fascinating and informative facts, such as abnormalities in the anatomic features of the common atrioventricular valve ${ }^{13-15}$ and the cardiac venous system..$^{15,16}$ These specific findings, which differ from those in hearts with usual atrial arrangement, almost certainly have major clinical significance. They support strongly our view that the cardiac malformations in patients with visceral heterotaxy are more precisely described, and more reasonably unified, according to the most constant morphologic features within the heart itself rather than on the basis of any other extracardiac features. Although it depends on the individual investigator whether or not the atrial arrangement according to the morphology of the appendages is to be used as the basis for stratifying patients with visceral heterotaxy, ${ }^{17}$ it is surely a gross exaggeration to state that the morphology of the atrial appendages is of no surgical or clinical significance. ${ }^{18}$

It is our further opinion that knowledge of this morphologic background is helpful in establishing the optimal surgical strategies when planning to perform the Fontan type of procedure in patients with visceral heterotaxy and right isomerism. As had been noted by many clinicians, maintenance of an optimal pulmonary circulation is one of the most important aspects, and control of regurgitation through the common atrioventricular valve is another. With properly organized surgical strategies, the chances of achieving the most efficient Fontan circulation are markedly increased. Several operative procedures have been reported. Because of the complicated abnormal venoatrial connections, use of an intracardiac tube graft $^{19}$ is obviously an attractive choice. Indeed, this was our chosen procedure in our previous series of patients. ${ }^{15,20}$ Our current preference, however, as with Mainwaring and Lamberti, ${ }^{1}$ is to use the extracardiac Gore-Tex tube graft. This is, in part, because we choose to do the operation without the aid of cardiopulmonary bypass, employing temporary bypass from the caval veins to the atrial cavity. $^{21}$ By this maneuver, we believe that we circumvent the deleterious influences of cardiopulmonary bypass on the pulmonary circulation known to occur immediately following the standard Fontan type procedure. In addition, we are able to complete the procedure without the need for transfusion of blood. The technique can also be used in patients with independent drainage of the hepatic veins, a frequent finding in those with visceral heterotaxy, by using dual temporary bypasses. ${ }^{21}$ When constructing an extracardiac channel, it is also possible to use a pedicled autologous pericardial roll for draining the inferior caval venous blood into the pulmonary arteries. ${ }^{21,22}$ In terms of potential for growth and anticoagulability, such autologous tissues are probably better than prosthetic materials. Use of a $14 \mathrm{~mm}$ diameter prosthetic tube could prove insufficient for unobstructed inferior caval venous drainage when the patient becomes an adolescent. Peel formation inside the prosthesis may also promote earlier obstruction within the channel.

Another advantageous aspect of the extracardiac Fontan is to minimize the pulmonary venous obstruction which can be the consequence of placement of an intracardiac conduit. ${ }^{23}$ We have experienced problems subsequent to use of an intracardiac conduit in 2 patients with visceral heterotaxy. In one patient with left isomerism, an $18 \mathrm{~mm}$ Gore-Tex tube placed within the left-sided atrium obstructed the left-sided atrioventricular valvar orifice. In this particular patient, the rightsided atrioventricular valve was severely stenotic. After the initial intraatrial grafting, the atrial pressure for the systemic circulation was high because of the obstruction at the ventricular inflow. The intraatrial graft was changed to a $14 \mathrm{~mm}$ tube on the fifth postoperative day. This down-sizing vastly improved the intraatrial obstruction. The patient is now doing well. In the other patient, with right 
isomerism, pulmonary venous obstruction occurred and progressed at more than 2 years after the establishment of the Fontan circulation. This patient underwent removal of the intracardiac tube graft during planned conversion to bidirectional Glenn physiology. At the time of reoperation, it proved that a part of the intracardiac conduit was adherent to the orifice for the pulmonary venous channel. It seemed that the fibrous adhesions were formed because of the short distance between the prosthetic tube placed intraatrially and the pulmonary venous orifice. The unfavourable progress was related, therefore, to the abnormal orientation of the systemic and pulmonary venous orifices. Presence of an abnormal pulmonary venous connection to the atrial chamber, with the so-called common pulmonary venous chamber having an orifice with a fibrous ridge, was another possible contributory factor. In these patients, such problems would have been prevented had an extracardiac channel been constructed for the inferior caval venous drainage.

Even when constructing an extracardiac channel, the surgeon should be well aware of orientation of the venoatrial connections. Because of the unusual location of the orifice of the inferior caval vein, and that of an independent hepatic vein if any, the extracardiac channel can be long and tortuous, and may be compressed by the mass of the heart. The surgeon should, of course, construct the extracardiac channel so as to avoid obstruction as well as turbulence. By combining such technical improvements with precise knowledge of the morphology of the malformed hearts, overall surgical and functional results after the Fontan type procedure can surely be improved still further, even in patients with visceral heterotaxy and complex intracardiac malformations.

\section{References}

1. Mainwaring RD, Lamberti JJ. Extracardiac conduit Fontan for children with heterotaxy and functionally single ventricle. Cardiol Young 1998; (in press).

2. Uemura $H$, Yagihara T. Surgical treatment in patients with isomeric atrial appendages. In: Yacoub $\mathrm{MH}$, Carpentier AF. Annual of Cardiac Surgery, 10th edition. London: Rapid Science Publishers, 1997:105-112.

3. Uemura H, Ho SY, Devine WA, Kilpatrick LL, Anderson RH. Atrial appendages and venoatrial connections in hearts from patients with visceral heterotaxy. Ann Thorac Surg 1995; 60: 561-569.

4. Rubino M, Van Praagh S, Kadoba K, Pessotto R, Van Praagh $R$. Systemic and pulmonary venous connections in visceral heterotaxy with asplenia: diagnostic and surgical considerations based on seventy-two autopsied cases. J Thorac Cardiovasc Surg 1995; 110: 641-650.

5. Van Praagh S, Kreutzer J, Alday L, Van Praagh R. Systemic and pulmonary venous connections in visceral heterotaxy, with emphasis on the diagnosis of the atrial situs: a study of 109 postmortem cases. In: Clark E, Takao A, eds. Developmental Cardiology, Morphogenesis and function. Mt. Kisco, New York: Futura Publishing; 1990: 671-721.

6. Ruscazio M, Van Praagh S, Marrass AR, Catani G, Iliceto S, Van Praagh R. Interrupred inferior vena cava in asplenia syndrome and a review of the hereditary patterns of visceral situs abnormalities. Am J Cardiol 1998; 81: 111-116.

7. Sapire DW, Ho SY, Anderson RH, Rigby ML. Diagnosis and significance of atrial isomerism. Am J Cardiol 1986; 58: 342346.

8. Van Mierop LHS, Wiglesworth FW. Isomerism of the cardiac atria in the asplenia syndrome. Lab Invest 1962; 11: 13031315.

9. Ho SY, Seo JW, Brown NA, Cook AC, Fagg NL, Anderson RH. Morphology of the sinus node in human and mouse hearts with isomerism of the atrial appendages. $\mathrm{Br}$ Heart 1995; 74: 437-442.

10. Dickinson DF, Wilkinson JL, Anderson KR, Smith A, Ho SY, Anderson RH. The cardiac conduction system in situs ambiguous. Circulation 1979; 59:879-885.

11. Ho SY, Fagg N, Anderson RH, Cook A, Allan LD. Diposition of the atrioventricular conduction tissues in the heart with isomerism of the atrial appendages: its relation to congenital complete heart block. J Am Coll Cardiol 1992; 20: 904-910.

12. Uemura $H$, Yagihara $T$, Kawashima $Y$, Okada K, Anderson $\mathrm{RH}$. The earliest site of atrial activation in patients with isomeric appendages. Br Heart J 1995; 74: 305-309.

13. Uemura H, Ho SY, RH Anderson, Kilpatrick LL, Yagihara Y, Yamashita K. The nature of the annular attachment of common atrioventricular valves in hearts with isomeric atrial appendages. Eur J Cardio-thorac Surg 1996; 10: 540-545.

14. Uemura $H$, Anderson RH, Ho SY, Devine WA, Neches WH, Smith A, Yagihara T, Kawashima Y. Left ventricular structures in atrioventricular septal defect associated with isomerism of atrial appendages compared to similar fearures with usual atrial arrangement. J Thorac Cardiovasc Surg 1995; 110 : 445452.

15. Uemura $H$, Anderson RH, Yagihara T. Surgical implications in hearts with isomeric atrial appendages. In: Karp RB, Laks $H$, Wechsler AS, eds. Advances in Cardiac Surgery, volume 7. St. Louis: Mosby-Year Book, Inc., 1996: 101-135.

16. Uemura $\mathrm{H}, \mathrm{Ho} \mathrm{SY}$, Anderson RH, Devine WA, Smith A, Shinohara T, Yagihara T, Kawashima Y. The surgical anatomy of coronary venous return in hearts with isomeric atrial appendages. J Thorac Cardiovasc Surg 1995; 110 : 436-444

17. Uemura H, Ho SY, Devine WA, Anderson RH. Analysis of visceral heterotaxy according to splenic status, appendage morphology, or both. Am J Cardiol 1995; 76: 846-849.

18. Geva T, Vick GW III, Wendt RE, Rokey R. Diagnosis of heterotaxy syndrome [reply to the Editor]. Circulation 1995; 91 : 907-908.

19. Humes RA, Feldt RH, Porter CJ, Julsrud PR, Puga FJ, Danielson GK. The modified Fontan operation for asplenia and polysplenia syndrome. J Thorac Cardiovasc Surg 1988; 96: $212-218$

20. Uemura H, Yagihara T, Kawashima Y, Yamamoto F, Nishigaki K, Matsuki O, Okada K, Kamiya T, Anderson RH. What factors affect ventricular performance after a Fontan-type operation? J Thorac Cardiovasc Surg 1995; 110 : 405-415.

21. Uemura H, Yagihara T, Yamashita $K$, Ishizaka T, Yoshizumi K, Kawahira Y. Establishment of total cavopulmonary connection with no use of cardiopulmonary bypass. Eur J Cardio-thorac Surg 1998; (in press). 
22. Hvass U, Pnaes Y, Bohm G, Depoix JP, Emguerrand D, Worms AM. Bicaval pulmonary connection in tricuspid atresia using an extracardiac tube of autologous pediculated pericardium to bridge inferior vena cava. Eur J Cardio-thorac Surg 1992; 6: 49-51.
23. Berman W, Fripp RR, Yabek SM. Late-onset pulmonary venous pathway obstruction after Fontan operation: presentation masquerading as intra-atrial baffle leakage. Pediatr Cardiol 1997; 18: 49-51. 